\title{
CONSTRUCTION PLANNING ASSIST METHOD USED CONSTRUCTION MODEL
}

\author{
Yoshihisa Masamura \\ Kajima Technical Research Institute \\ Kajima Corporation \\ 19-1,Tobitakyu 2-chome,Chofu-shi,Tokyo 182-0036,Japan \\ masamura@kajima.com
}

\begin{abstract}
The study of construction planning assist method using information technology is being continued steadily. However, the practical planning assist methods like a automatically checking construction plan instantaneously have not been proposed. The purpose of this paper is to provide functional and practical new construction planning assist method using construction model. Authors developed Erection Planning System applied for erection checking. This system has the function to set automatically suitable traveling crane at the appropriate location, and is used practically. The activity validation checking extended the erection checking of the Erection Planning System is core function of the new construction planning assist method. The activity validation checking consist of milestone checking, structure checking, space inference checking, equipment specification limits checking, activity time checking, component preceding checking and stocks checking. The construction model related to the new assist method is computer model linked activity data and building component data. Keywords: construction model, construction planning, assist method, activity checking method, information technology
\end{abstract}

\section{INTRODUCTION}

A lot of Studies for construction simulation used three dimensional shape data were reported. As an example of these studies, AI-Hussen et al. ${ }^{1)}$ developed lift planning assist method having optimum algorithm of mobile crane configurations. This algorithm use geometrics, three dimensional length, lift capacity and known lift planning logic.

In the studies for method assisting a whole part of construction, there are studies of schedule visualization. As the study of the origin of schedule visualization studies, Fischer/Aalami ${ }^{2}$ developed the method which generates process model consisting of activities sequence, from building model and construction method model. Koo/ Fischer $^{3)}$ did the feasibility study about four dimensional CAD being possible schedule visualization, and presented to be able to assist the construction planning of a variety of work specimens. Chau et $\mathrm{al}^{4)}$ reported an applicable example about four dimensional schedule visualization. They represented simultaneously building erection schedule chart and erection bird's-eye view at computer screen. This study shows that the schedule visualization method linked activities of schedule chart to components of building view, is practical stage.

Recently, there are remarkable studies for work space allocation applied for 4-diemnsion(time/space) model . Akinci et al. ${ }^{5,6)}$ reported automatic generation of work space volume and duration used 4-diemnsion product model and work space data. Guo ${ }^{7)}$ developed decision assist tool to solve space conflict required temporary work spaces in site plane. So far, many studies for construction planning assist methods/tools using 4-diemnsion(time/space) model linked three dimensional component data to construction schedule data, were executed. However, these tools are not ordinarily utilized in construction sites. This reason is assumed that current assist tools used 4-diemnsion model have insufficient assist functions.

\section{OBJECT}

The purpose of this paper is to provide functional and practical new construction planning assist method. This assist method is related to construction model linked activity data and building component data. A part of the function of this assist method is the function of the Erection Planning System ${ }^{8), 9)}$ which authors have developed. To extend assist region of this developed system, clear concept was indispensable. In this paper, at first, author introduces the Erection Planning System, secondary presents the new construction planning method extended the assist method of the Erection Planning System.

\section{ERECTION PLANNING SYSTEM}

\subsection{Basic specifications}

The object of the Erection Planning System is to assist basic erection plan-making. This system checks execution possibility of erection about each erection component. The checking items consist of crane lift capacity limits checking and space interference checking between crane-beam/lifting -component and built components. The work specimen dealing with this system is erection work which is one of the several work specimens related to erection. Temporal loading work, welding work and so on are not deal by this system. Unit of erection work activity is ordinary a group of components erecting in one day. The Erection Planning System assists basic erection planning, dose not assist detailed erection planning. The activity of this system has precedence of erection, and has not start and finish time. In this system, hierarchical grouping of erection work activity 
was executed. Also, construction work area was assumed to be similar to erection work activity area.

\subsection{Contents of Erection Planning System}

\subsubsection{Whole constituent}

Showing figure1., Erection Planning System consists of erection component model generation module, activity generation module and erection checking module. There are two methods generating erection component model. One is manual input used modeler. The other is automatic input from three dimensional CAD data. Output of this module is a component weight table. In the activity generation module, the components belongs to each activity are extracted from erection component model and activity precedence is designated. Outputs of this module are a table of numbers of components and drawings of components of activities. In the erection checking module, the execution possibility of erection work is checked under designated crane position and specification. The checking results are showed by means of checking results tables and erection bird's-eye views. This system is implemented using Visual Basic for application in AutoCAD environment and Excel.

\subsubsection{Erection component model generation}

The component specimens being used by Erection Planning System are column, beam, vertical strut, brace and the other component. By inputting adjacent buildings and temporary facilities like a scaffolding to erection component model, the erection checking considered these conditions becomes possible. As the weight calculation functions of this module, there are component weight calculation from component volume, separation of column segment, adding bracket of beam part to column segment, and modification of component weight. In the modification of component weight, multiplied coefficient and adding weight are set to components of designated component specimens or components selected from three dimensional drawing of erection component model. Also, the direct manual input of component weight is possible.

\subsubsection{Activity generation}

The Erection Planning System has activity hierarchical structure consisting of four classes. The names of activity hierarchical classes are in term of large class, middle class, small class and special small class from upper to lower hierarchical structure. The special small class which is the lowest class of activity hierarchical structure, is an aggregate of components. The small class is an aggregate of special small classes, and so on. The activity of large activity class is building part erected by one erection team with a crane. The use of the other activity class(middle/small/ special small class) is free style. As generating methods of activity classes, there are the method dividing upper class to lower class, the method integrating lower class to upper class and the method mixing divide and integration. Activity generating sequence becomes activity precedence in default. Selecting current generating activity, numbers of components and crane working time related the activity have been calculated and displayed in computer screen. The crane working time is calculated using erection time of one component of each

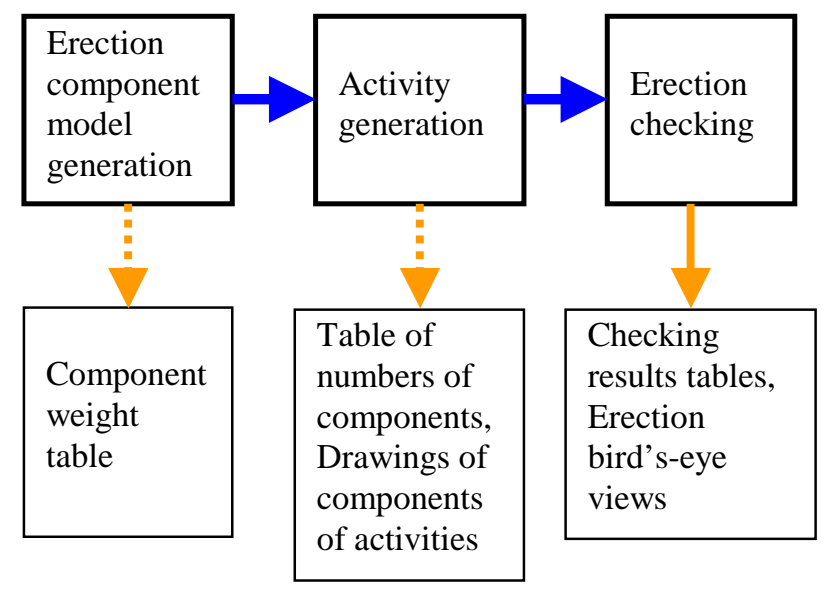

Figure 1. System constituent and output

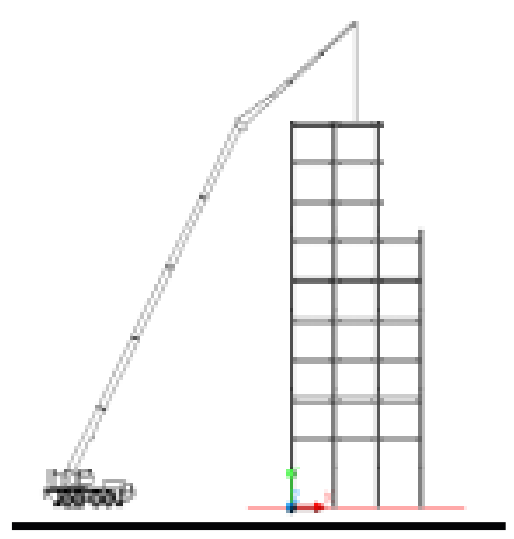

Figure2. Interference between crane beam and built components

component specimen. There is an option function assisting the modification of activity precedence. The object of this function is to determine automatically activity of the beam supported columns belongs to various activities. This function sets the activity of the beam to the successor activity in various activities of columns.

\subsubsection{Erection checking}

Erection checking consists of two checking items having details. Details of crane specification limits checking item are work distance checking and lift capacity checking. Details of space interference checking item are lift height checking and contact checking which calculates whether crane boom contacts built components or not. Figure2. shows Interference between crane beam and built components. The contact checking criteria is the shortest distance between central axis of crane beam and central axis of built components. In the case of the shortest distance less than two meter, contact checking is failure. The value of the contact checking criteria can be modified on computer display. The crane is located at the position linked to an activity of designated activity class (large/middle/small /special small).

As the methods of crane positioning, there are the method of crane positions direct input and the method of 

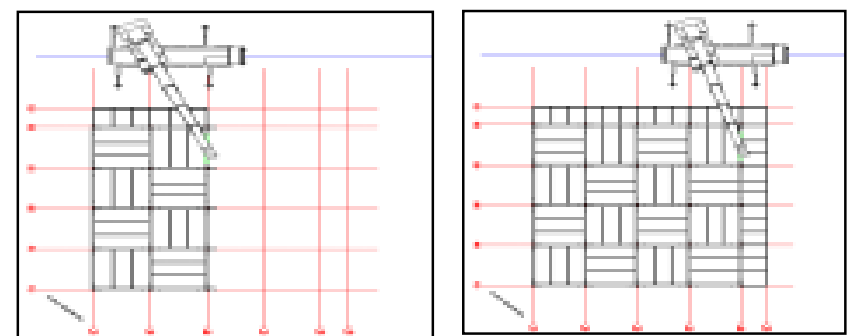

Figure 3. The automatic change of crane position on crane traveling path

Table1. The specification of $\mathrm{N}$ building

\begin{tabular}{|l|l|}
\hline Numbers of floor & 7 th \\
\hline Structure & $\begin{array}{l}\text { Steel and reinforced } \\
\text { concrete (SRC) }\end{array}$ \\
\hline Building height & $28.9 \mathrm{~m}$ \\
\hline Site area & $6,300 \mathrm{~m}^{2}$ \\
\hline Building area & $600 \mathrm{~m}^{2}$ \\
\hline Sum of floors area & $4,700 \mathrm{~m}^{2}$ \\
\hline $\begin{array}{l}\text { Numbers of erection } \\
\text { components }\end{array}$ & $\begin{array}{l}\text { Steel components: } 600 \mathrm{p} \\
\text { Curtain walls: } 100 \mathrm{p}\end{array}$ \\
\hline
\end{tabular}

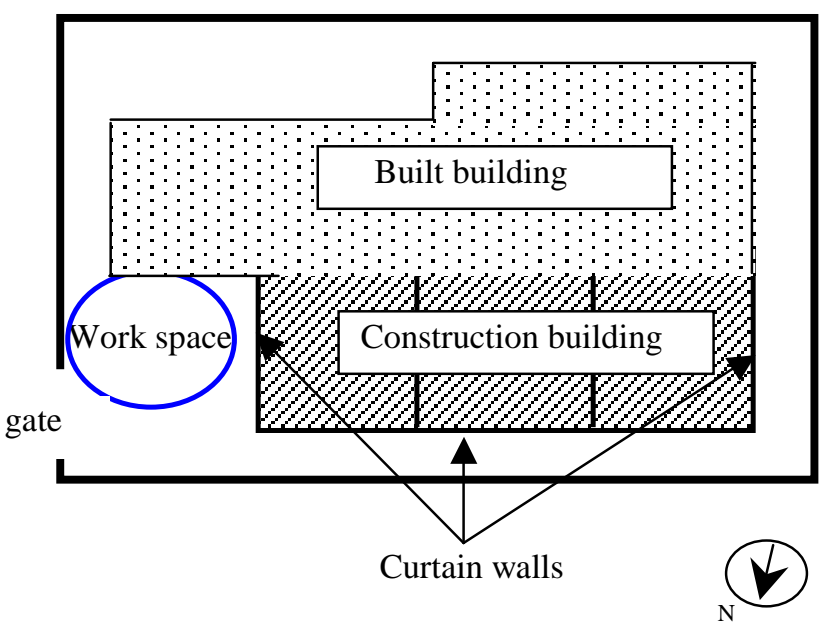

Figure4. Site configuration

crane traveling path setting. Figure 3 . shows the automatic change of crane position on crane traveling path. The Initial automatic setting crane position on the raveling path is the location which have the shortest distance to central position of activity components area. If the result of erection checking is failure in the initial setting crane position, the Erection Planning System repeatedly relocates crane position on the traveling path until results of erection checking become success(no failure) or the most minimum failed components.

The erection checking results are represented tables and drawings. Also, the checking values of components selected from three dimensional components view are displayed on the computer screen.

The crane types using erection checking are fifteen hydraulic/crawler types as traveling crane and three tower types as fixed crane.

\subsection{Example of practical use}

\subsubsection{The abstract of $\mathrm{N}$ building erection}

The Erection Planning System was applied for $\mathrm{N}$ building erection. Table1. shows the specification of $\mathrm{N}$ building. Figure4. shows the site configuration of this construction. The frame of $\mathrm{N}$ building has 3 spans toward east-west direction, and column separate 4 segments ( 2 stories/segment). Curtain walls made of concrete are located at north, east and west faces, and are erected by a crane. Initial erection plan was erection used a tower crane, because work space is limited in urban region.

To reduce erection cost, erection plan used a traveling crane which is cheaper than a tower crane was studied. The space located a traveling crane is construction building area and east side area of construction building, therefore there was necessity to study erection method of curtain walls made of concrete of west side face. The Erection Planning System was applied for 2 plans suggested by building team.

3.3.2 Apply of the Erection Planning System

(1) Plan A

Plan A; at first all steel components are erected by a traveling crane, secondary curtain walls made of concrete are erected by the bigger traveling crane. The steel components of a span of building frame are allotted to an activity, and activity precedence is set from west to east. Erection checking was executed about 100,120,160,200ton traveling crane on traveling path toward east-west direction. As a result of this erection checking, it was cleared that all steel components were able to erect by the crane more than 160 ton traveling crane. Also, it was validated that west side face curtain walls were able to erect over construction building by 200ton traveling crane adding lattice type jib in east side. (Figure5. )

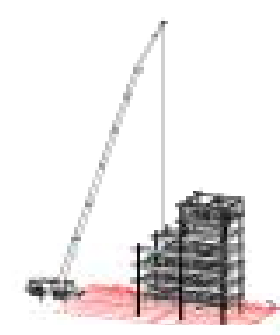

a) Central zone steel components erection

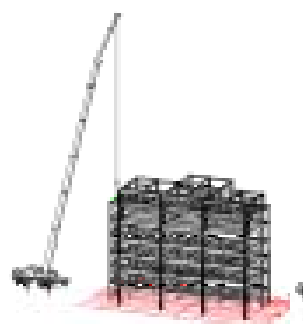

b) Steel components erection completed

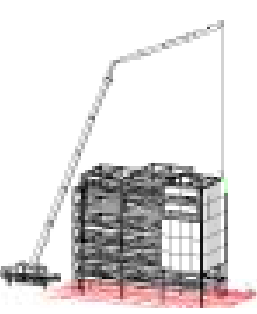

c) West side curtain walls erection
Figure5. Erection bird's-eye view of Plan A

\section{(2) Plan B}

Plan B; steel components and curtain walls made of concrete are simultaneously erected from west to east direction. Activity generation and traveling path setting of 
Plan B was similar to Plan A. Erection checking was executed about 160,200ton traveling crane on traveling path toward east-west direction. As a result of this erection checking, it was cleared that the main boom of a crane would contact with a built beam, erecting west side face curtain walls by a 160ton crane. Plan B was modified like that the beam would erect after erection of west side face curtain walls to avoid contact. Using modified Plan B, erection checking was executed. (Figure 6. )

As a result of this erection checking, it was cleared that all components were able to erect by 160ton traveling crane. Figure 7. shows erection bird's-eye view of Plan B.
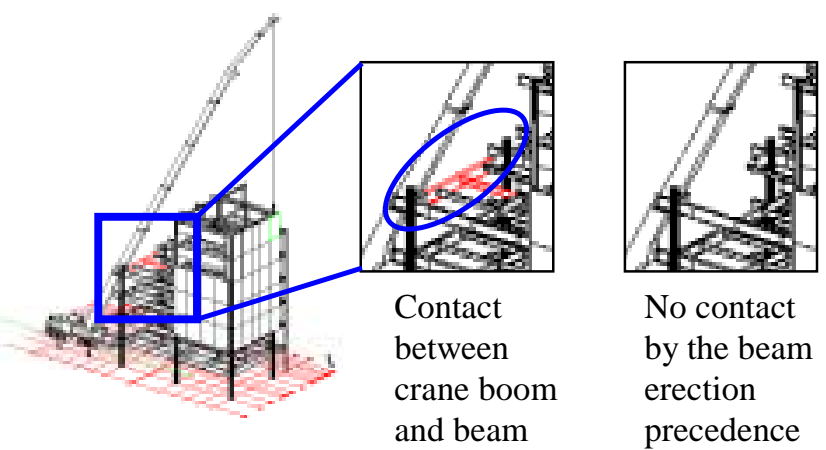

No contact by the beam erection precedence changed

Figure6. Detailed erection drawings

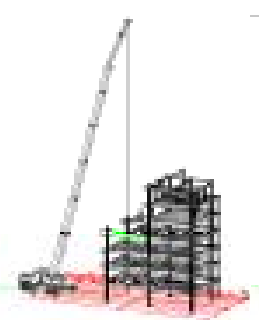

a) West side steel components erection completed

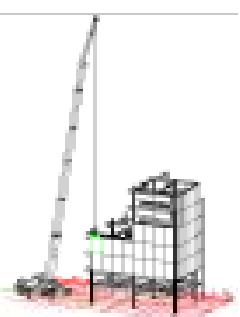

b) West side curtain walls erection completed

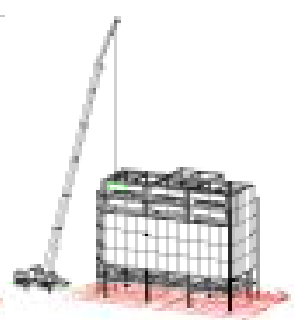

c) All components er" 全ection completed
Figure7. Erection bird's-eye view of Plan B

\subsubsection{Application results}

The following results were obtained from the example of practical use; (1) the problem of erection plan was detected in early planning stage, (2) the selection of crane type was executed in short time.

\section{NEW CONSTRUCTION PLANNING ASSIST METHOD}

4.1 Concept

The concept of new assist method derives from the idea of the erection checking used by Erection Checking System. A Construction plan consists of activities having many work specimens in addition to an erection work specimen. Under the condition that data related to activity is taken in computer, the checking of activity execution possibility and activity obeying construction period limit is possible using checking rules (computer algorithm). Also, the automatic setting of construction parameters used the checking results is possible. Author named this assist method "activity checking method". New proposed activity checking method is the construction planning assist method which performs validity checking of activity data made by planner and construction parameter setting as possible as computer can. The construction model which is used by activity checking method consists of product data, construction condition data, temporary facilities data work-specimen/work-specimen -precedence data, resource data and activity data.

\subsection{Activity checking method}

\subsection{1 checking items}

Table2. shows the checking items in activity checking method and the functions of the checking items. Milestone checking item is the checking of activity obeying construction period limit. The other six checking items are the checking of activity execution-possibility. For all checking items related to work specimen belongs to the activity, checks are executed about the component or the activity one by one.

Table2. The checking items in activity checking method

\begin{tabular}{|l|l|}
\hline Checking item & \multicolumn{1}{|c|}{ Function } \\
\hline $\begin{array}{l}\text { Milestone } \\
\text { checking }\end{array}$ & $\begin{array}{l}\text { Dose the activity time exceed to } \\
\text { milestone time? }\end{array}$ \\
\hline $\begin{array}{l}\text { Structure } \\
\text { checking }\end{array}$ & $\begin{array}{l}\text { Strength and deformation } \\
\text { checking after setting up of } \\
\text { components }\end{array}$ \\
\hline $\begin{array}{l}\text { Space } \\
\text { interference } \\
\text { checking }\end{array}$ & $\begin{array}{l}\text { Space interference checking under } \\
\text { set-up/material traveling/works }\end{array}$ \\
\hline $\begin{array}{l}\text { Equipment } \\
\text { specification } \\
\text { limits } \\
\text { checking }\end{array}$ & $\begin{array}{l}\text { Checking the specification limit } \\
\text { like a lift capacity of crane }\end{array}$ \\
\hline $\begin{array}{l}\text { Activity time } \\
\text { checking }\end{array}$ & $\begin{array}{l}\text { Is the duration of work within } \\
\text { activity start/end time? }\end{array}$ \\
\hline $\begin{array}{l}\text { Component } \\
\text { precedence } \\
\text { checking }\end{array}$ & $\begin{array}{l}\text { In component-work start time, are } \\
\text { all predecessors of this } \\
\text { component-work completed ? }\end{array}$ \\
\hline $\begin{array}{l}\text { Stocks } \\
\text { checking }\end{array}$ & $\begin{array}{l}\text { Checking of the spare amount of } \\
\text { temporary facilities stocks }\end{array}$ \\
\hline
\end{tabular}

\section{4 .2.2 Construction model}

Applying for the checking rules of activity checking method, the construction model linked activity data and component data is indispensable. Figure8. shows supposed construction model utilization. The utilization of construction is divided four stages. At component data input 
stage (Figure8. (a) ), by means of manual input or automatic format conversion from the other system data, component data is generated in the construction model. Simultaneously, data for structure checking and data for connection relations between components are generated as a part of component data.

At activity generation stage (Figure8. (b) ), by means of manual input and data transportation from DB, a variety of construction data is input in the construction model. In addition, Planner generates activities used automatically extracting components belongs to component specimen which related to work specimen. Activity checking rules can be used through activities generating stage. In this stage, construction plan data consisting of activity data, resource (labor, equipment, temporary facilities) data, milestone data and work area/traveling path data is generated.

At plan selection/plan modification stage (Figure8. (c)), planner selects optimum plan from several construction plans and modifies selected plan. Modified activity data is automatically checked by activity checking rules.

At construction stage (Figure8. (d) ), completed activity data and working activity data are Input in construction model, and current plan is re-planning. Assist stages of activity checking method are activity generation stage, plan selection/plan modification stage and construction stage.

\section{4 .2.3 Automatic setting of planning parameters}

Activity checking method is possible to execute automatic setting of construction parameter used activity validation checking results. As specimens of construction parameter, there are activity time, work area separation, work specimen precedence, intermediate milestone and resource (labor, equipment, temporary facilities). For automatic parameter value setting, planner has to designate parameter specimen, parameter initial value, the range of parameter values and the priority modification sequence of parameters.

\section{4 .2.4 Characteristics of activity checking method}

The first characteristic of activity checking method is the point that the core function of this method is activity validation checking which is possible using the checking rules and construction data including shape/position of component. The application of checking rules is not limited by specimens of work, because checking rules is general. We will expect that the function of activity validation checking is very useful to reduce mis-planning.

The second characteristic of activity checking method is the point that the construction plan used this assist method is generated as construction model in computer. The drawings of construction plan are produced from this construction model. In the meeting of building teams at construction site applying for this assist method, plan modification and plan checking is instantaneously possible.

\section{4 .3 Relation between activity checking method and critical pass method}

As construction assist method, critical pass method (CPM) is generally used. Activity checking method uses

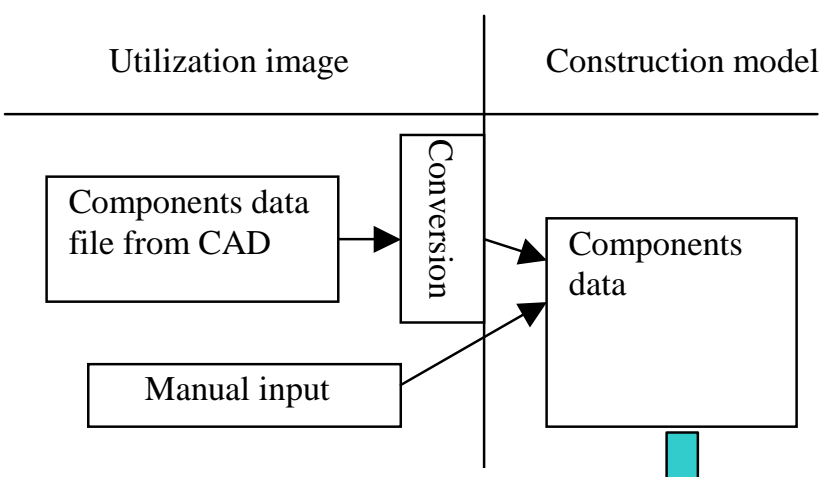

(a) Components data input

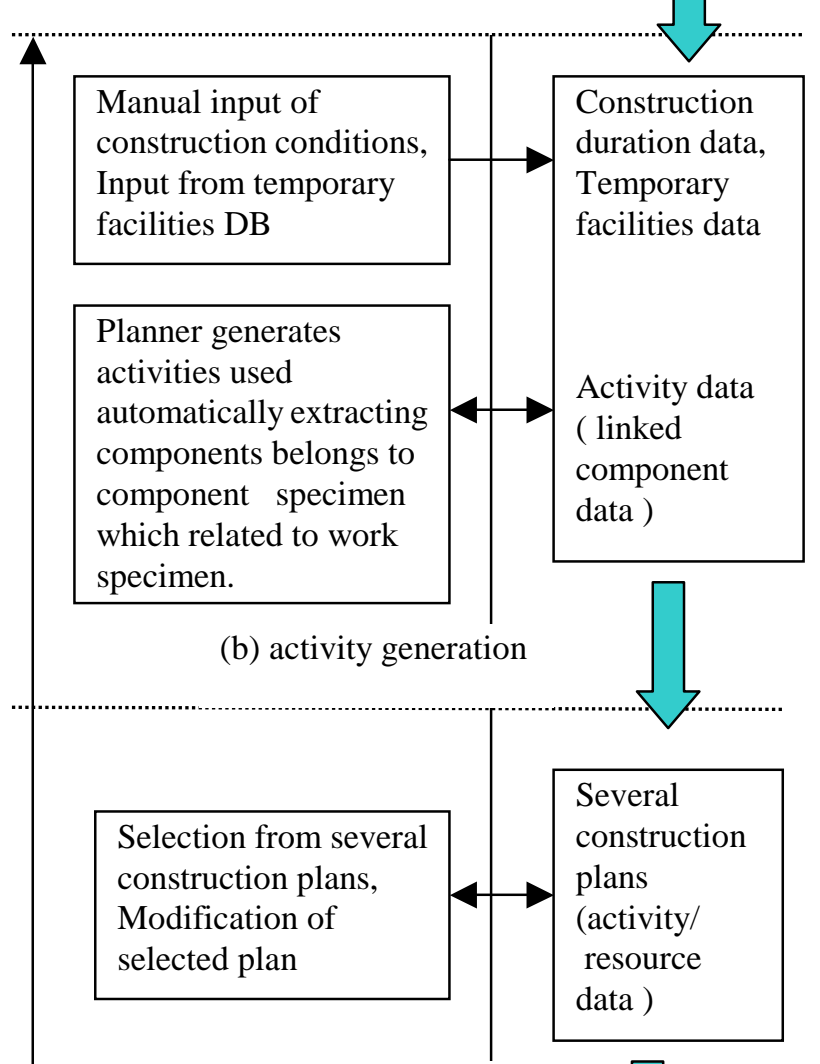

(c) plan selection, plan modification

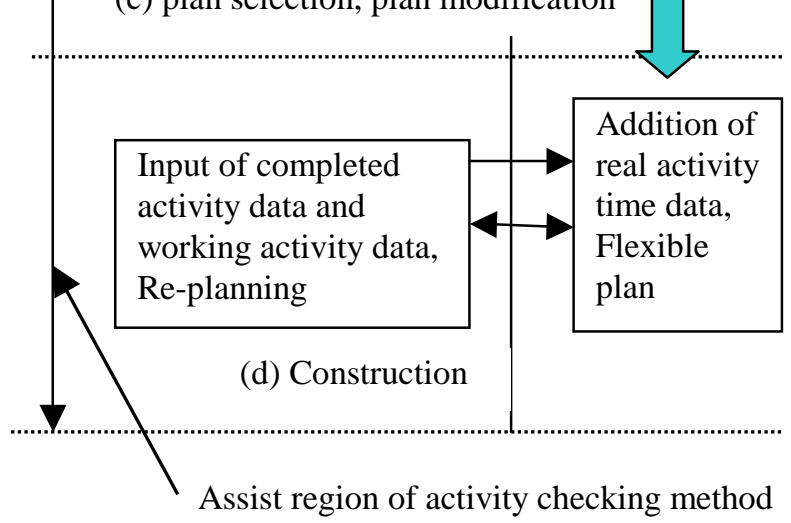

Figure8. Supposed construction model utilization 
Table3. The comparison of activity checking method and CPM

\begin{tabular}{|c|c|c|}
\hline & $\begin{array}{l}\text { Activity checking } \\
\text { method }\end{array}$ & CPM \\
\hline 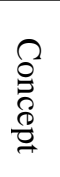 & $\begin{array}{l}\text { Construction } \\
\text { simulation method } \\
\text { based on activity } \\
\text { validation checking }\end{array}$ & $\begin{array}{l}\text { General simulation } \\
\text { method based on } \\
\text { Graph Theorem }\end{array}$ \\
\hline 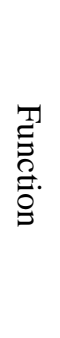 & $\begin{array}{l}\text { Checking of activity } \\
\text { execution possibility } \\
\text { and activity obeying } \\
\text { construction period } \\
\text { limit, Automatic } \\
\text { setting construction } \\
\text { parameter used } \\
\text { checking results }\end{array}$ & $\begin{array}{l}\text { Calculation of } \\
\text { critical path, } \\
\text { Activity earliest } \\
\text { start/finish time, } \\
\text { Activity latest start/ } \\
\text { finish time, } \\
\text { Activity total/free } \\
\text { float }\end{array}$ \\
\hline 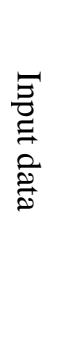 & $\begin{array}{l}\text { Component data, } \\
\text { Construction } \\
\text { duration, Work } \\
\text {-specimen } \\
\text { precedence, } \\
\text { Resource data } \\
\text { ( labor, equipment, } \\
\text { temporary facilities) }\end{array}$ & $\begin{array}{l}\text { Activity label, } \\
\text { Activity duration, } \\
\text { Activity } \\
\text { precedence }\end{array}$ \\
\hline 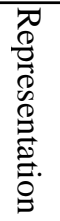 & $\begin{array}{l}\text { Bar chart, Building } \\
\text { diagram in } \\
\text { construction } \\
\text { process, Checking } \\
\text { result table }\end{array}$ & $\begin{array}{l}\text { Network diagram, } \\
\text { Calculation results } \\
\text { table }\end{array}$ \\
\hline
\end{tabular}

activity data similar to CPM. However, the concept and function of activity checking method are different from CPM. Table3. shows the comparison of activity checking method and CPM. The concept of CPM is theory oriented idea, and the calculation of CPM is based on Graph Theorem. The other hand, the concept of activity checking method is function oriented idea, and the methods of calculation are based on checking rules. The simple function and simple input data of CPM produce wide range general use.

The complex function and complex input data of activity checking method make possible to assist detailed construction planning. The representation of schedule from activity checking method is bar chart, because the diagram of the network based on component precedence checking results is too complex.

From table3., it is clear that CPM is efficient for initial construction planning using a few data, and activity checking method is effective for detail construction planning using a variety of data. As a conclusion, the relation of activity checking method and CPM is complementary about construction planning assist.

\section{SUMMRY}

A part of new proposed activity checking method was being validated by the development of Erection Planning System. The activity checking method performs checking of activity execution possibility, checking of activity obeying construction period limit and automatic setting construction parameter used checking results. The construction model related to activity checking method is the model linked activity data and component data. By inputting of completed activity data and working activity data in the construction model, the utilization of the construction model is extended from construction planning to construction management. Using activity checking method, We will be expected to reduce mis-planning and to raise productivity.

\section{REFERENCES}

[1]AI-Hussen M.,Alkass S. and Moselhi O. : "Optimization Algorithm for Selection and on Site Location of Mobile Cranes" J. of Construction Engineering and Management, ASCE , MAY 2005, P.579-590

[2]Martin A.Fischer, Florian Aalami :"SCHDULING WITH COMPUTER-INTERPRETABLE CONSTRUC TION METHOD MODELS" J. of Construction Engineering and Management, ASCE, DECEMBER 1996, P.337-347

[3]Bonsang Koo, Martin Fischer : "FEASIBILITI STUDY OF 4D CAD IN COMMERCIAL CONSTRUCTION" $\mathrm{J}$. of Construction Engineering and Management, ASCE, AUGUST 2004, P.598-606

[4]K.W.Chau,M.Anson,J.P.Zhang : "Four-Dimensional Visualization of Construction Scheduling and Site Utilization" J. of Construction Engineering and Management, ASCE, JULY/AUGUST 2002, P.296-305

[5]Burcu Akinci, Martin Fischer, John Kunt, Ray Levitt : "Representing Work Spaces Generically in Construction Method Models" J. of Construction Engineering and Management, ASCE, JULY/AUGUST 2002, P.296-305

[6]Burcu Akinci, Martin Fischer, John Kunt : "Automated Generation of Work Spaces Required by Construction Activities" J. of Construction Engineering and Management, ASCE, JULY/AUGUST 2002, P.306-315

[7] Sy - jye Guo : "Identification and Resolution of Work Space Conflicts in Building Construction" J. of Construction Engineering and Management, ASCE, JULY/AUGUST 2002, P.287-295

[8]Yoshihisa Masamura, Hajime Kaneko: "Development and Application of Building Erection Planning System (patt1) Abstract of Building Erection Planning System" Proceedings of Academic Symposium on Hokkaido Convention, AIJ, 2004, P.673-674

[9] Hajime Kaneko, Yoshihisa Masamura: "Development and Application of Building Erection Planning System (patt2) Application of Building Erection Planning System" Proceedings of Academic Symposium on Hokkaido Convention, AIJ, 2004, P.675-676 